News and Views

\title{
A Study of Urartian Metallurgy Techniques Case Study: Urartian Bronze Weaponry in the Reza Abbasi Museum
}

\author{
Poorya Kashani $^{a^{*}}$, Bita Sodaei ${ }^{\mathrm{a}}$, Shahram Heydarabadian ${ }^{\mathrm{b}}$, Behrooz Paranj ${ }^{\mathrm{c}}$ \\ ${ }^{a}$ Department of Archaeology, Varamin-Pishva Branch, Islamic Azad University, Varamin, Iran \\ ${ }^{b}$ Reza Abbasi Museum, Tehran, Iran \\ 'Metallography Laboratory, Science and Research Branch, Islamic Azad University, Tehran, Iran
}

\section{ARTICLE INFO}

\section{Article history:}

Received: 18 December 2012

Accepted: 1 July 2013

\section{Key words:}

metallography

forging

casting

annealing

twinning

slip band

\begin{abstract}
$A B S T R A C T$
Urartian bronze armours and harnesses in the Reza Abbasi Museum, which had been previously analysed by PIXE (Particle Induced X-ray Emission), have been studied once again in order to obtain additional information concerning metallurgy of the time. For a better understanding of Urartian metalworking, all of these ten items have been studied with a metallographic microscope. The study determined that Urartian metalworkers were experimentally familiar with certain physical properties of the elements. These known properties include the flexibility and approximate melting points of the metals. The forms of the twinnings and slip bands reveal that all of the alloys underwent annealing and forging treatments. After heating to at least $650^{\circ} \mathrm{C}$, hot-forging and cold-forging was carried out, depending on the form, usage and importance of the artefacts. After these steps, final annealing was carried out on the alloys.
\end{abstract}

\section{Introduction}

The Urartian territory contained rich deposits of mineral ores: copper, iron, lead and tin. It is therefore not surprising that the Eastern part of Anatolia is considered one of the earliest metallurgy centres and that the Urartian bronze weaponry artefacts display a high level of artistic skill and decorative art (Piotrovskii 1969).

Research on ancient metal objects plays a significant role in reaching an understanding of the technological specialisation of the time. Elemental analysis and studies of metal microstructures are types of characterization researches in the field of archaeometry. Archaeometry is a term coined by archaeologists for the application of science-based approaches to archaeological problems. It applies directly to all aspects of archaeology and anthropology. Archaeometry is an academic field which concerns the study of a wide variety of archaeological artefacts (Hammond 1974).

There are two types of metal objects which can be used in order to obtain information about metal production

"Corresponding author. E-mail: poorya_kashani@iauvaramin.ac.ir processes: final products and waste products. Each of these may be analysed for different purposes. All of the artefacts under study are kinds of artefacts and can be consequently viewed as final products. Analysis of the final products can determine alloying, casting, working practices as well as the possible ore sources utilised (Thornton et al. 2008). Based on the information recorded in the Museum, these artefacts belong to the Urartian period. Urartu (860-590 BC) was an ancient kingdom situated in what is now Armenia, Eastern Turkey and North-western Iran (Piotrovskii 1969).

The ten artefacts under study are housed in the Reza Abbasi Museum. The Museum policy is to house artefacts rescued from antiquities trade or looting. The abovementioned items had been formerly analysed by PIXE in the Van de Graaff laboratory of the Atomic Energy Organization of Iran (AEOI). The results of that analysis, which are dedicated to the chemical compositions of the armour and harness fragments, are mentioned in Table 1. In this table, each object is marked with a special museum code. Items numbers 138 and 139 are studied as a single object, in that, they are two parts of an object which had been damaged and separated. Based on the chemical compositions, it has been 
concluded that these samples are low-tin bronzes. The high amounts of copper and tin indicate that these two had been extracted separately from chalcopyrite and cassiterite and melted together. The variation in the $\mathrm{Sn}$ amounts illustrates that the ratio of $\mathrm{Sn}$ to $\mathrm{Cu}$ had been determined experimentally by Urartian metalworkers (Kashani et al. 2013).

In this study, for a better understanding of Urartian alloy production processes, metallographic examinations have been conducted on the artefacts in order to investigate the microstructure of these $\mathrm{Cu}-\mathrm{Sn}$ alloys.

\section{Sample preparation}

The samples were obtained by scalpel from the metal cores in the damaged and marginal parts of the objects. Further operations were carried out in the metallurgical laboratory of Islamic Azad University, Science and Research Branch.

Due to the high flexibility of copper and also to protect the metal microstructures, cold mounting was conducted in epoxy (Geels 2007). The diameters of the moulds were $1 \mathrm{~cm}$. Surface mechanical preparation of the metallographic specimens was consequently carried out with various methods of grinding, polishing and etching. The mounted specimens were wet ground with abrasive papers with a $400 \mathrm{Mesh}$ which was gradually increased to 1,200 , to reveal the metal surface. In order to produce a smooth surface, the abrasive papers were applied horizontally and vertically intermittently. The specimens were consequently mechanically polished with metallographic wet polishing equipment. The wet polishing was performed with the presence of $\mathrm{Al}_{2} \mathrm{O}_{3}$.

The last step prior to the microscopic examination was the etching. The metallographic etching is the process of revealing microstructural details which would otherwise not be evident on the as-polished sample. There are three ways for etching: chemical etching, electrolytic etching and heat tinting. Chemical etching is the most common etching method for specimens which are not corrosion-resistant (Scott 1991). Therefore, in this case, the etching operation was applied chemically with a solution of $\mathrm{FeCl}_{3}(2.5 \mathrm{~g}), \mathrm{HCl}$ (2 ml) and $\mathrm{C}_{2} \mathrm{H}_{5} \mathrm{OH}(50 \mathrm{ml})$.

\section{Results and discussion}

Metallographic techniques are used to study the components and physical structures of ceramics, metals and alloy polished sections with the use of a microscope which reflects light passing through the objective lens onto the specimen surface (Scott 1991).

In this study, metallographic analyses were observed and compared at $500 \mathrm{X}$. First, the properties of the two main elements, $\mathrm{Cu}$ and $\mathrm{Sn}$ (Table 1), were introduced. Copper has a Face-Centered Cubic (FCC) lattice structure while the tin lattice structure is Body-Centered Tetragonal (BCT). Metals with FCC structures can be mechanically deformed, drawn out into wire, and hammered into sheets. The melting point for copper is $1,084.62^{\circ} \mathrm{C}$ while that of tin is $231.93^{\circ} \mathrm{C}$. Therefore, where rates of $\mathrm{Sn}$ increase, the melting point of bronze alloys decreases. According to Figure 1, the melting point for $10 \% \mathrm{Sn}$ and $90 \% \mathrm{Cu}$ is approximately $900^{\circ} \mathrm{C}$, although alloys in hot-working should be heated to near red

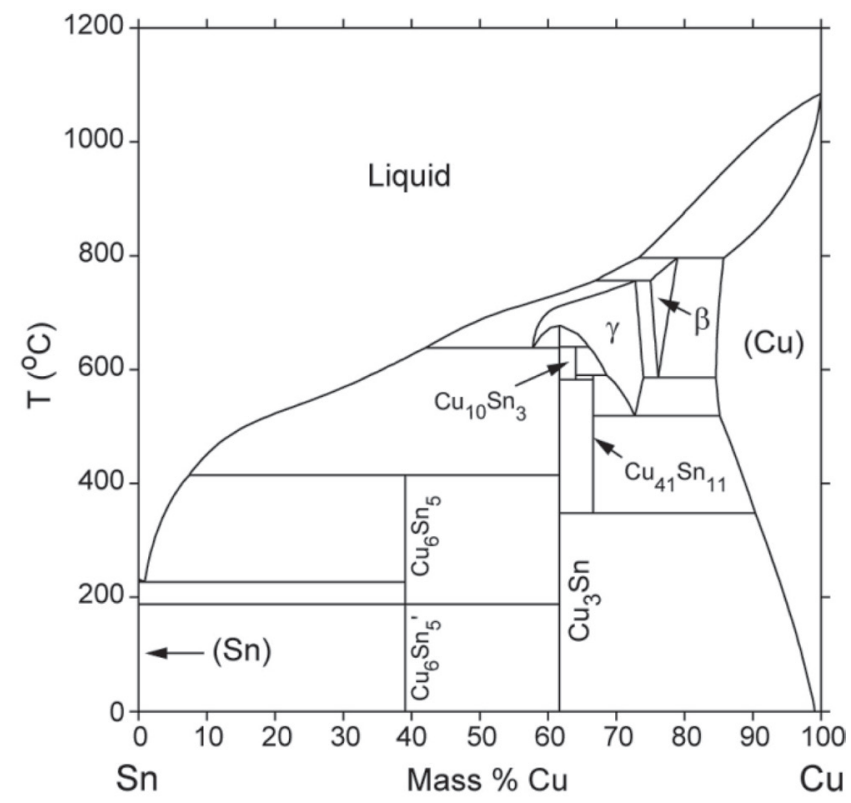

Figure 1. Phase diagram of $\mathrm{Cu}-\mathrm{Sn}$.

Table 1. Element composition of selected copper-based Urartian bronze artefacts, Reza Abbasi Museum (Kashani et al. 2013).

\begin{tabular}{ccccccc}
\hline Row & Object Code & Ti (\%) & Fe (\%) & Cu (\%) & Sn (\%) & Others \\
\hline 1 & $138-139$ & - & 0.15 & 89.75 & 10.10 & - \\
2 & 788 & 0.07 & 0.34 & 95.74 & 3.85 & - \\
3 & 789 & - & 0.55 & 91.88 & 7.57 & - \\
4 & 791 & - & 0.74 & 90.02 & 9.24 & - \\
5 & 134 & 0.21 & 1.55 & 82.00 & 15.73 & Mn: $0.51 \%$ \\
6 & 799 & 0.09 & 1.45 & 90.76 & 7.70 & - \\
7 & 796 & 0.09 & 1.35 & 91.55 & 7.01 & - \\
8 & 137 & - & 0.14 & 87.69 & 12.17 & - \\
9 & 792 & 0.18 & 2.29 & 91.38 & 6.15 & - \\
10 & 148 & - & 0.09 & 86.31 & 13.11 & Zn: $0.49 \%$ \\
\hline
\end{tabular}




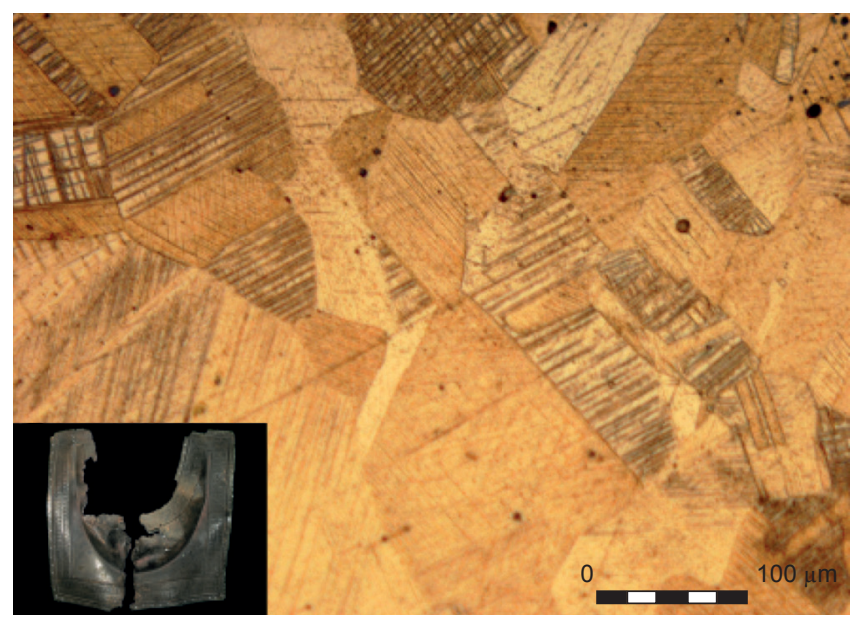

Figure 2. Metallographic photo, object 138-139 (armour shoulder cover).

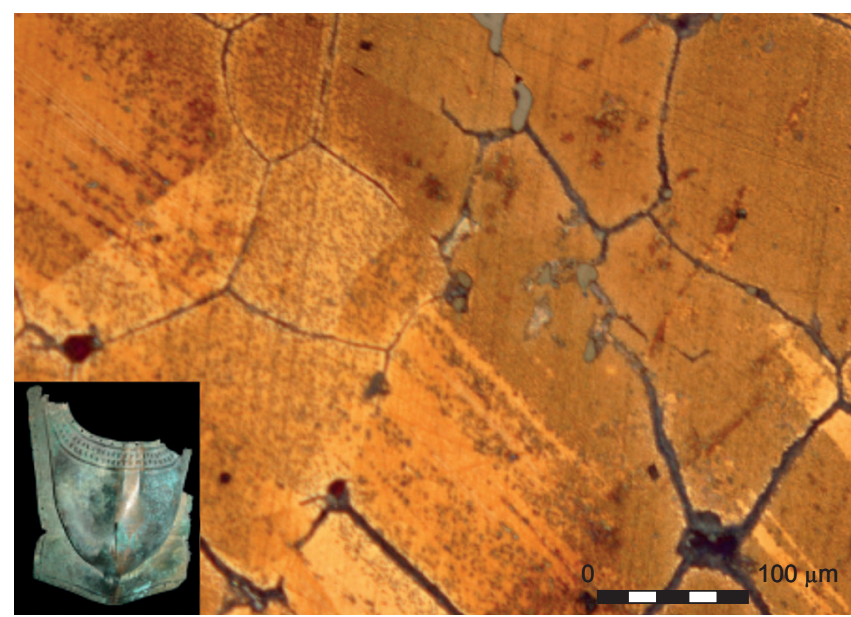

Figure 4. Metallographic photo, object 789 (armour shoulder cover).

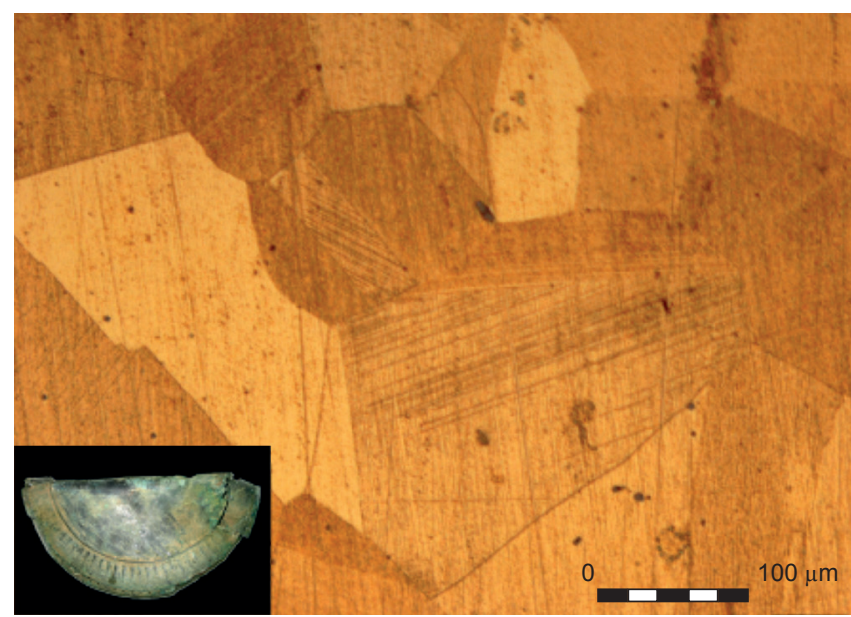

Figure 6. Metallographic photo, object 134 (armour chest cover).

heat which in these cases is approximately $650^{\circ} \mathrm{C}$ with the formation of phase $\beta$. At this time, for hot-working, objects should be hammered immediately.

FCC metals, apart from Al, recrystallize through a twinning process (Scott 1991). Twinnings, as parallel straight lines,

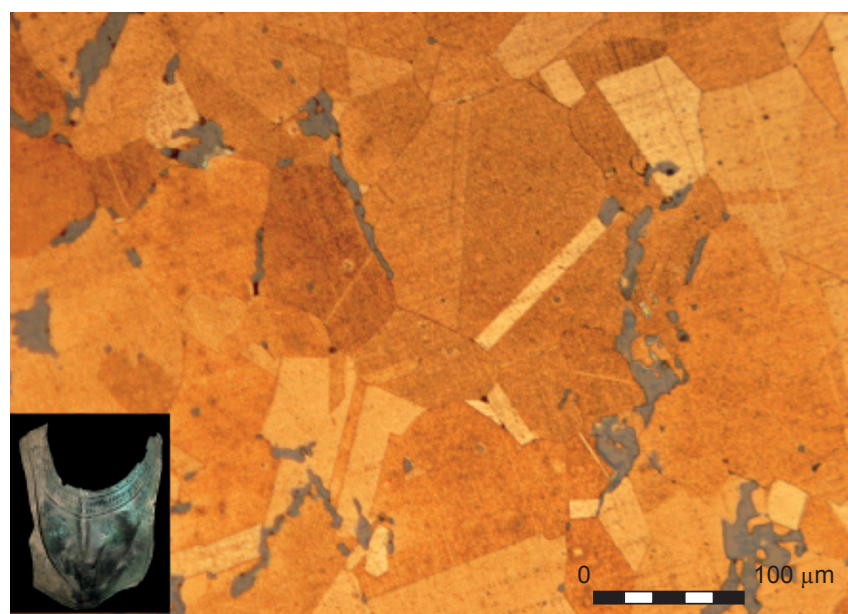

Figure 3. Metallographic photo, object 788 (armour shoulder cover).

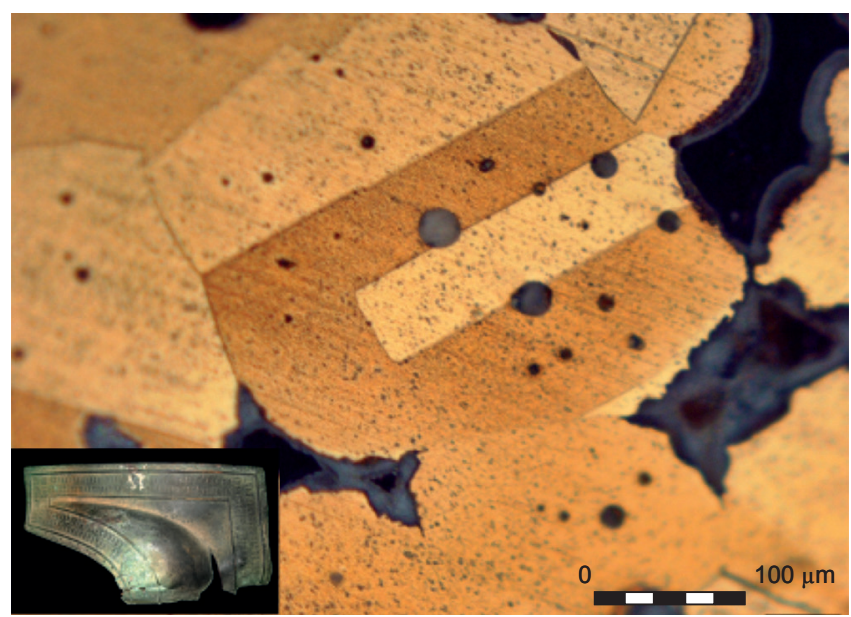

Figure 5. Metallographic photo, object 791 (armour shoulder cover).

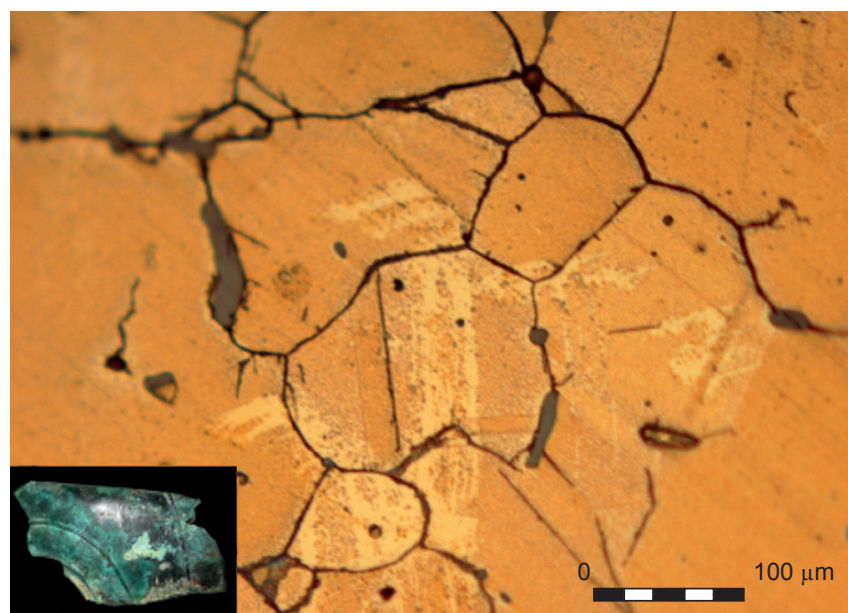

Figure 7. Metallographic photo, object 799 (unknown).

can be seen in all the figures which can indicate the annealing process. These exact parallel lines can also illustrate the final annealing operations.

In addition, strain lines (slip bands) in the forms of fine lines in a number of the grains can be observed in the 


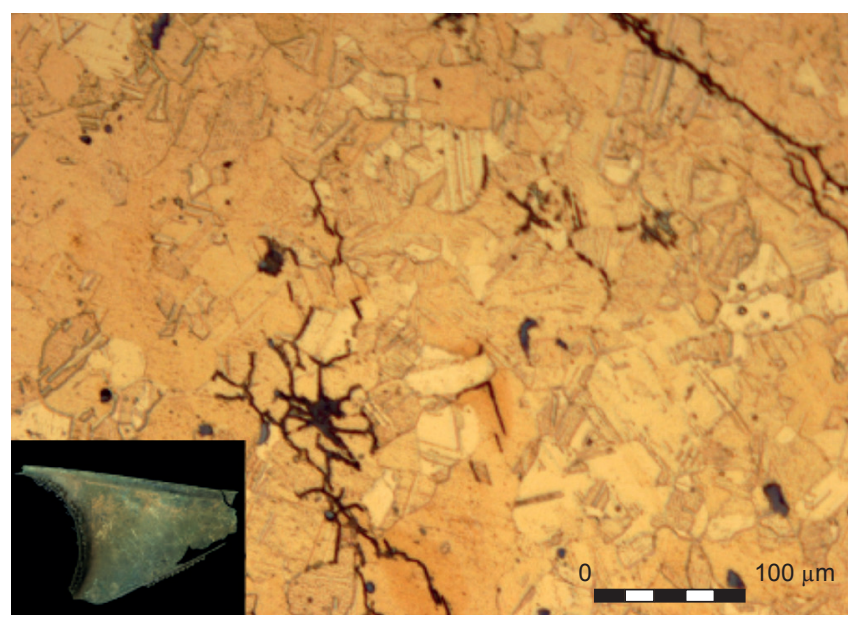

Figure 8. Metallographic photo, object 796 (armour shoulder cover).

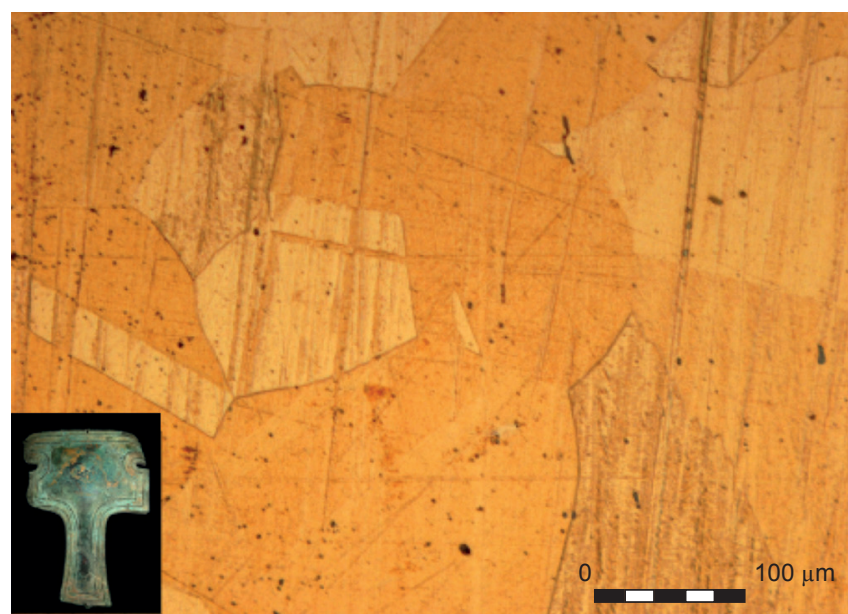

Figure 10. Metallographic photo, object 792 (harness).

samples. This can indicate heavy working on the dendrite microstructure and on the deformed grains. One might therefore argue that in such cases cold-working has been carried out after annealing. It would seem that the items under study were manufactured initially in the forms of sheets and then converted into the desired shapes. Considering the usage of the artefacts, it also seems likely that the strain lines caused by cold-workings were the results of marks made by weapons during wars or the engraving processes.

Metallographic photos of the cross sections of the samples are shown in Figures 2-11. The image of each object is placed below the relevant figures. Each item usage is also mentioned in the descriptions. As can be seen in the figures, all the samples, apart from 796, are moderate grained, approximately equiaxed and have an annealed microstructure with numerous annealing twins evident. In Figure 3, 4, 5, 7 and 8 precipitates are observed. Based on the above, the hammering operations were carried out on all the alloy objects but apparently this was most applied to object 796. This can be concluded from the small sizes of the fine grains which can be seen in Figure 8. Figure 8, unlike the other artefacts, reveals an extremely fine grain

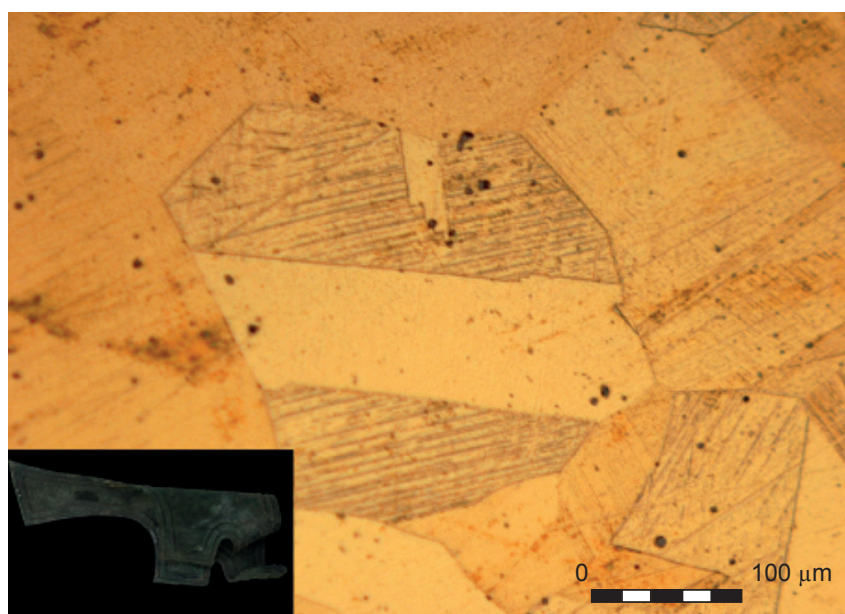

Figure 9. Metallographic photo, object 137 (harness).

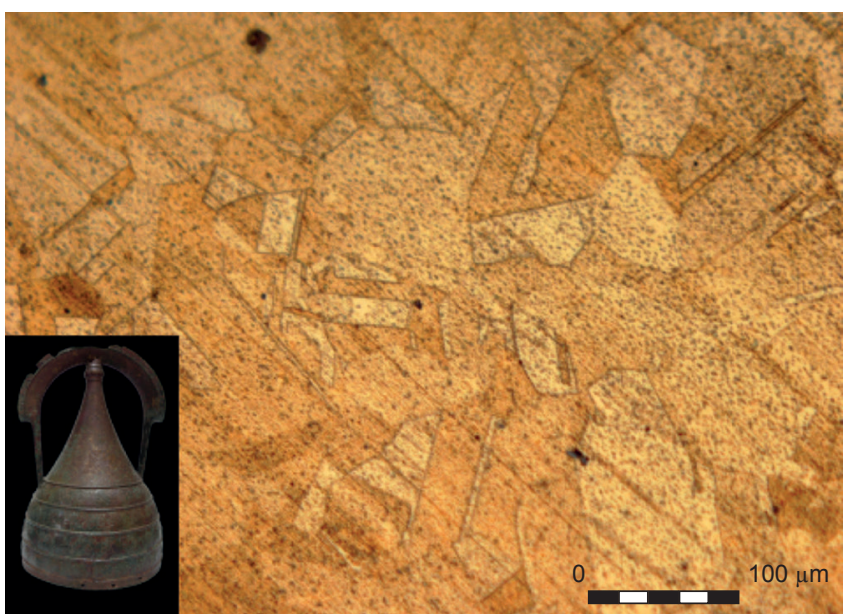

Figure 11. Metallographic photo, object 148 (helmet).

size with no significant porosity. The grains are equiaxed with limited evidence of annealing twins. Object 796, was in all probability worked and reheated several times during the shaping operation (Pigott et al. 2003).

\section{Conclusion}

The metallographic photos reveal that a number of the metallurgical skills were fairly developed in Urartian civilization. In the Urartian bronze armour and harness production processes, after extracting the main elements $\mathrm{Cu}$ and $\mathrm{Sn}$ from their mineral ores and mixing them together, the craftsmen heated these bronze artefacts up to approximately $650^{\circ} \mathrm{C}$ which is red heat temperature in order to achieve sufficient deformation of the initial materials.

After this step, hot-hammerings were conducted to produce metal sheets and form them. Designs were consequently engraved via cold-hammerings on these bronze objects. In the last stage, the metals underwent final annealing. The metallographic photos also indicate several marks made by weapons during wars. 


\section{References}

GEELS, K. 2007: Metallographic and Materialographic Specimen Preparation, Light Microscopy. In: Fowler, D. B., Kopp, W.-U., Rückert, M. (Eds.): Image Analysis, and Hardness Testing. ASTM International.

HAMMOND, P. C. 1974: Archaeometry and Time: A Review. Journal of Field Archaeology, Vol. 1, No. 3/4, 329-335.

KASHANI, P., KHADEMINADOOSHAN, F., SHABANISAMGHABADI, R., ABROOMAND AZAR, P., OLIAIY, P. 2013: PIXE analysis on Urartian bronze armors and harnesses in the Reza Abbasi Museum, Iran, Mediterranean Archaeology and Archaeometry, Vol. 13, No. 1, 127-133.
PIGOTT, V. C., ROGERS, H. C., NASH, S. K. 2003: Archaeometallurgical Investigations at Malyan, The Evidence for tin-Bronze in the Kaftari Phase, In: Miller, N. F., Abdi, K. (Eds.): “yeki bud, yeki nabud”, Essays on the Archaeology of Iran in Honor of William M. Sumner. The Costen Institute of Archaeology, University of California, Los Angeles, USA.

PIOTROVSKII, B. 1969: The Ancient Civilization of Urartu. Translated from the Russian by James Hogarth, Barrel and Rockliff, London, UK.

SCOTT, D. A. 1991: Metallography and Microstructure of Ancient and Historic Metals, The Getty Conservation Institute, The Paul Getty Museum.

THORNTON, C. P., REHREN, T., PIGOTT, V. C. 2008: The Production of Speiss (Iron Arsenide) during the Early Bronze Age in Iran. Journal of Archaeological Science, Vol. 36, 308-316. 
